Website: http://journal.umy.ac.id/index.php/mrs

DOI: $10.18196 / \mathrm{jmmr} .5117$.

\title{
Health Belief Model pada Kepatuhan Hand Hygiene di Bangsal Berisiko Tinggi Healthcare Acquired Infections (HAIs) (Studi Kasus Pada Rumah Sakit X)
}

\author{
Merita Arini* \\ *Penulis Korespondensi: merita.arini@yahoo.com \\ *Magister Manajemen Rumah Sakit Universitas Muhammadiyah Yogyakarta

\begin{tabular}{|c|c|}
\hline INDEXING & $A B S T R A C T$ \\
\hline Keywords: & as a global problem, patient morbidity and mortality in hospital caused by Healthcare Acquired \\
\hline health belief model & Infections (HAIs) can be prevented by implementation of Hand Hygiene (HH). This research aims to \\
\hline precaution & study by survey approach and cross-sectional design. The population consisted all of nurses in high \\
\hline & risk HAIs ward (ICU and surgical ward, 30 respondents). HCW's perceptions were measured \\
\hline & $\begin{array}{l}\text { HH. HH compliance should be increase. Workplace factor had significant influence to } H H \\
\text { compliance. }\end{array}$ \\
\hline
\end{tabular}

(C) 2016 JMMR. All rights reserved

Article history: received 25 Jul 2016; revised 19 Okt 2016; accepted 25 Nov 2016

\section{PENDAHULUAN}

Healthcare-associated infection (HAIs) adalah infeksi yang berkembang pada pasien/ staf di setting pelayanan kesehatan dan terkait dengan aktivitas mendapatkan/ memberi pelayanan. ${ }^{1}$ HAIs terjadi di seluruh dunia (rata-rata 8,7\%) dengan jenis terbanyak adalah infeksi luka operasi/ ILO. Berdasarkan ruang rawatnya, prevalensi HAIs tertinggi di ICU dan bangsal bedah. ${ }^{2}$ Data dari 10 RS pendidikan Indonesia menunjukkan insidensi HAIs cukup tinggi (6-16\%, rata-rata 9,8 \%) dengan infeksi terbanyak adalah ILO. ${ }^{3}$

HAIs menjadi penyebab mayor kematian dan peningkatan morbiditas dengan beban ekonomi dan sosial yang besar. Mengingat besarnya dampak HAIs, diperlukan upaya pencegahan dan pengendalian infeksi (PPI). PPI yang efektif di USA dapat mereduksi HAIs $32 \%$, menyelamatkan 1578 nyawa pasien; mencegah 81.020 hari pemondokan; dan menyelamatkan biaya $\$$ 165.534.736. ${ }^{4}$ Praktik-praktik utama PPI meliputi kewaspadaan standar serta kewaspadaan tambahan sesuai transmisi penyakit. Hand hygiene adalah lini pertama dan utama dalam kewaspadaan standar. Pada kenyataannya, kepatuhan staf kesehatan sebagai ujung tombak pelayanan kesehatan dalam penerapan hal tersebut di atas pada umumnya masih rendah. ${ }^{5}$
RSU X dalam penelitian ini adalah RS swasta tipe C bersertifikat ISO 9001:2000 yang pada saat dilakukan penelitian sedang dalam proses perisapan akreditasi KARS untuk kategori RS dengan 12 pelayanan. Oleh karena itu, RS memerlukan upaya peningkatan kepatuhan hand hygiene dengan mengkaji faktor-faktor yang mempengaruhinya secara holistik.

Faktor-faktor yang berpengaruh terhadap penerapan hand hygiene terutama di bangsal-bangsal yang memiliki risiko HAIs tertinggi adalah hal yang patut dikaji. Studi ini menggunakan pendekatan Health Belief Model (HBM) yang meliputi kajian atas persepsi atas kerentanan (perceived susceptibility) dan keseriusan (severity) HAIs, manfaat (benefit) dan hambatan (barrier) menerapkan kewaspadaan standar, cues to action (trigger untuk menerapkan), kepercayaan diri mampu menerapkan (self efficacy), dan modifying variables (jenis kelamin, umur, tingkat pendidikan, riwayat cidera/ penyakit/ kontak, status kepegawaian, tempat, dan lama bekerja) terhadap hand hygene. ${ }^{5}$ 


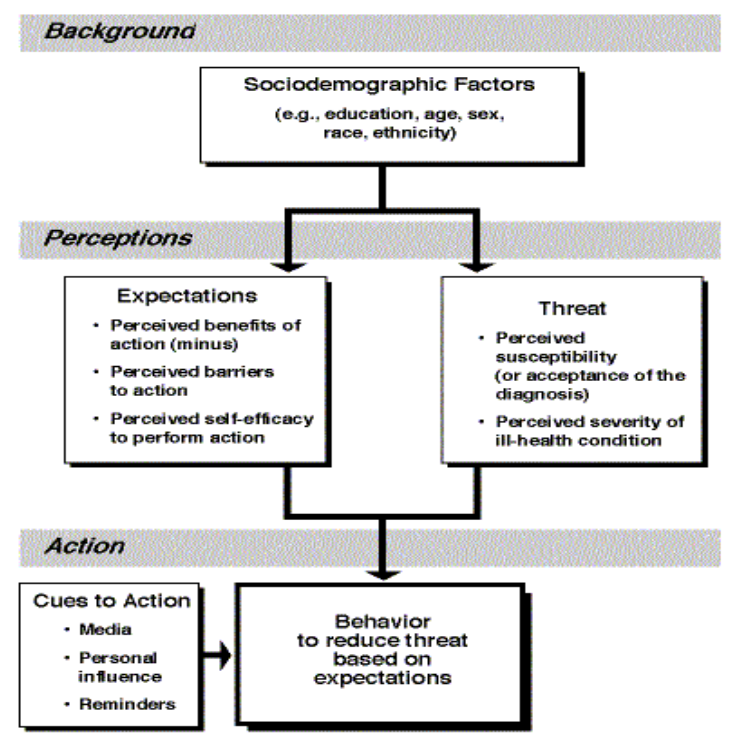

Sumber: Rosenstock, Strecher, \& Becker (1994) cit Denison (1996)

Tujuan penelitian ini adalah mengetahui mengetahui pengaruh masing-masing persepsi serta modifying variables terhadap kepatuhan hand hygiene staf.

\section{METODE PENELITIAN}

\section{Jenis dan Rancangan Penelitian}

Jenis penelitian ini adalah kuantitatif dengan desain cross sectional melalui pendekatan survey. Subyek penelitian adalah perawat yang bekerja di RSU $\mathrm{X}$ di salah satu kabupaten Provinsi DIY. Obyek penelitian berupa perilku penerapan hand hygiene, persepsi dan variabel modifikasi staf. Penelitian dilaksanakan di bangsal berisiko tinggi HAIs (ICU dan bangsal bedah) pada bulan April 2012. Populasi penelitian adalah seluruh perawat ICU dan bedah (total sampling). Didapatkan 30 orang responden. Kriteria inklusi meliputi bersedia menjadi responden dan tidak sedang libur/ cuti.

Instrumen penelitian meliputi lembar observasi: hand hygiene (mengacu pada daftar tilik kepatuhan HH RSUP Dr. Sardjito 20116 dan pedoman WHO 20067; serta kuesioner (mengacu pada konstruk HBM).

Perilaku diukur melalui observasi selama 1 hari pada masing-masing bangsal untuk menilai masingmasing staf selama 1 sihft jaga dengan membandingkan perilaku staf terukur dengan perilaku seharusnya. Masing-masing aspek kewaspadaan standar diberi range skor $0-10$, sehingga total kewaspadaan standar memiliki skor 0-30. Persepsi diukur dengan menggunakan skala likert (favorable 15, unfavorable 5-1) melalui kuesioner yang dibagikan dan diisi oleh staf.

\section{Uji Validitas dan Realibilitas}

Dalam penelitian ini digunakan pengukuran validitas konsep dengan uji korelasi Pearson Product Moment. Butir pertanyaan valid pada nilai $r$ hitung $>r$ tabel. Uji realibilitas dilakukan one shot dengan uji Cronbach's Alpha terhadap butir soal berskala likert. Soal reliabel pada alpha $>0,6$ (konstanta). ${ }^{10}$

Terhadap data-data dilakukan analisis deskriptif, kemudian uji normalitas dan analisis bivariat sesuai karakterisktik variabel (komparasi/ korelasi). Variabelvariabel dengan $\mathrm{p}<25$ pada analisis bivariat dimasukkan ke dalam analisis regresi berganda. ${ }^{11}$

\section{HASIL DAN PEMBAHASAN}

\section{Gambaran Umum RS X}

RS swasta milik salah satu organisasi masyarakat terbesar di Indonesia ini didirikan pada 1 Maret 1966 berawal dari sebuah Balai Pengobatan dan Rumah Bersalin (BP/ RB), RS Khusus Ibu dan Anak (1995),dan resmi menjadi RSU tipe C pada tahun 2001. RS yang bertempat di tengah kota salah satu kabupaten di DIY ini telah memiliki 127 tempat tidur, 278 karyawan tetap, dan 124 karyawan tidak tetap. Terdapat 14 dokter umum, 50 dokter spesialis, serta 5 dokter gigi. Terdapat 6 jenis pelayanan 24 jam, 15 poliklinik, 6 pelayanan penunjang, serta 9 pelayanan lain.

\section{Profil PPI RS X}

Organisasi Pencegahan dan Pengendalian Infeksi (PPI) dibentuk sejak Oktober 2011. Komite PPI terdiri atas 1 ketua (sekaligus dokter IPCO/ Infection Prevention and Control Officer), 2 sekretaris, dan anggota yang mewakili seluruh bagian RS. Terdapat 1 IPCN (Infection Prevention and Control Nurse)yang dibantu beberapa IPCLN (Infection Prevention and Control Link Nurse) di setiap unit. Komite PPI telah mengadakan pelatihan PPI, menyusun SOP (Standard Operating Procedure), melakukan kegiatan sosialisasi 
baik melalui forum, media cetak, maupun metodemetode lain, serta kerjasama/ koordinasi dengan bagian lain di RS yang terkait. Namun, mengingat masih barunya komite ini di RS tersebut, dalam pelaksanaannya masih terdapat beberapa kekurangan yang berdasarkan wawancara dengan staf komite PPI pada saat studi pendahuluan (10 Oktober 2011) diketahui bahwa belum optimalnya kinerja tim disebabkan kesibukan staf PPI yang merangkap jabatan RS fungsional/ struktural), belum terbentuk sistem monitoring dan evaluasi, belum terpenuhinya seluruh perlengkapan dan bahan untuk penerapan PPI.

\section{Hasil Uji Validitas dan Realibilitas}

Standardisasi alat dilakukan terhadap 30 responden di luar subyek penelitian yang memiliki kemiripan karakteristik dengan responden sesungguhnya. Seluruh butir soal dinyatakan valid karena $r$ hitung $>r$ tabel $(0,361$ pada level signifikansi 0,05 untuk $\mathrm{n}=30$ ) dan berada di atas cut off point 0,400. Hasil uji realibilitas menunjukkan bahwa hanya item soal pada sub-skala perceived severity dan benefit yang memiliki alpha $<0,6$ (konstanta), sehingga tidak reliabel. Soal pada sub-skala ini direvisi struktur katanya tanpa merubah makna, lalu dilakukan uji reliabilitas terhadap responden sesungguhnya. Didapatkan nilai alpha perceived severity 0,741 dan perceived benefit 0,823 . Maka, dapat dinyatakan bahwa seluruh butir soal kuesioner reliabel. ${ }^{10}$

\section{Karakteristik Responden}

Perawat ICU berjumlah 13 orang, 4 orang di antaranya tidak memenuhi kriteria inklusi, sedangkan perawag bangsal bedah 21 orang. Didapatkan jumlah responden 30 orang ( 9 perawat ICU dan 21 perawat bangsal bedah). Karakteristik responden/ modifying variables,dapat dilihat pada tabel 1 .

\section{Penerapan Hand Hygiene (HH / Perilaku Responden}

Berdasarkan efektivitas/ ketepatan prosedurnya, didapatkan data: (1) hanya terdapat 1 responden $(3,3$ \%) yang melakukan cuci tangan dengan 6 langkah efektif dan lamanya 40-60 detik. (2) Sebanyak 27 (93,1 \%) dari 29 responden yang menggunakan hand rub, melakukannya kurang dari waktu minimal yang seharusnya (20-30 detik). (3) Seluruh responden yang melakukan hand rub, tidak melakukannya dengan 6 langkah efektif.

Tabel 1. Karakter Responden

\begin{tabular}{|c|c|c|}
\hline Karakteristik & $\mathbf{n}$ & $\%$ \\
\hline \multicolumn{3}{|l|}{ Jenis Kelamin } \\
\hline Pria & 11 & 36,7 \\
\hline Wanita & 19 & 63,3 \\
\hline \multicolumn{3}{|l|}{ Umur(tahun) } \\
\hline $20-25$ & 6 & 20,0 \\
\hline $26-30$ & 13 & 43,3 \\
\hline $31-35$ & 8 & 26,7 \\
\hline $36-40$ & 2 & 6,7 \\
\hline $40-45$ & 1 & 3,3 \\
\hline \multicolumn{3}{|l|}{ Tingkat Pendidikan } \\
\hline SMA/K & 1 & 3,3 \\
\hline D3 & 26 & 86,7 \\
\hline $\mathrm{S} 1$ & 3 & 10 \\
\hline \multicolumn{3}{|l|}{ Status Kepegawaian } \\
\hline Pegawai Tetap & 15 & 50 \\
\hline Pegawai Kontrak & 10 & 33,3 \\
\hline Pengganti Cuti & 5 & 16,7 \\
\hline \multicolumn{3}{|l|}{ Lama Kerja(tahun) } \\
\hline $1-5$ & 21 & 70 \\
\hline $6-10$ & 6 & 20 \\
\hline $11-15$ & 3 & 10 \\
\hline \multicolumn{3}{|c|}{$\begin{array}{l}\text { Riwayat Pelatihan/ Sosialisasi } \\
\text { PPI }\end{array}$} \\
\hline Pernah & 28 & 93,3 \\
\hline Belum Pernah & 2 & 6,7 \\
\hline \multicolumn{3}{|c|}{ Riwayat Cidera Benda Tajam } \\
\hline Pernah & 25 & 83,3 \\
\hline Belum Pernah & 5 & 16,7 \\
\hline \multicolumn{3}{|c|}{ Riwayat Kontak Cairan Tubuh } \\
\hline Pernah & 17 & 56,7 \\
\hline Belum Pernah & 13 & 43,3 \\
\hline \multicolumn{3}{|l|}{ Riwayat Tertular HAIs } \\
\hline Pernah & 10 & 33,3 \\
\hline Belum Pernah & 20 & 66,7 \\
\hline
\end{tabular}

Kepatuhan $\mathrm{HH}$ seluruh responden berdasarkan moment sebesar 46,29\%. Kepatuhan perawat ICU lebih tingggi dibandingkan bedah (63\% vs. $38 \%)$. Berdasarkan moment, kepatuhan staf dapat dilihat dalam tabel 2. 
Tabel 2. Distribusi Responden dalam Kepatuhan Penerapan HH berdasar Saat/ Moment

\begin{tabular}{|c|c|c|c|c|}
\hline \multicolumn{2}{|c|}{ Saat/ Moment } & n & $\begin{array}{c}\mathrm{HH} \\
(\%)\end{array}$ & Tidak \\
\hline \multirow{7}{*}{ Sebelum } & kontak & 25 & 12 & 88 \\
\hline & dengan & & & \\
\hline & pasien & & & \\
\hline & tindakan & - & - & - \\
\hline & asepsis & & & \\
\hline & menggunakan & 24 & 20 & 80 \\
\hline & hand-scoen & & & \\
\hline \multirow{10}{*}{ Setelah } & kontakpasien & 28 & 68 & 32 \\
\hline & kontak cairan & 8 & 100 & - \\
\hline & tubuh pasien & & & \\
\hline & menggunakan & 26 & 50 & 50 \\
\hline & hand-scoen & & & \\
\hline & kontak & 19 & 74 & 26 \\
\hline & lingkungan & & & \\
\hline & Cuci tangan & 2 & - & 100 \\
\hline & setelah alcuta & & & \\
\hline & $5 \mathrm{x} /$ hand rub & & & \\
\hline
\end{tabular}

\section{Persepsi Responden}

Hasil analisis deskriptif variabel-variabel persepsi adalah sebagai berikut:

Tabel 1. Karakteristik Responden berdasarkan Umur

\begin{tabular}{|c|c|c|c|c|c|c|c|}
\hline Variabel/ Skor & $\mathbf{n}$ & Range & Maks. & Min. & Mean & Median & Std. Deviasi \\
\hline Perceived Susceptibility & 30 & $3-15$ & 15 & 8 & 12 & 12 & 2,05 \\
\hline Perceived Severity & 30 & $4-20$ & 20 & 8 & 15,20 & 16 & 2,29 \\
\hline Perceived Benefit & 30 & $3-15$ & 15 & 8 & 12,87 & 13 & 1,69 \\
\hline Perceived Barrier & 30 & $6-30$ & 29 & 15 & 22,27 & 22,50 & 4,28 \\
\hline Cues to Action (external/ ECA) & 30 & $3-15$ & 15 & 9 & 12,67 & 12 & 1,58 \\
\hline Self Efficacy & 30 & $3-15$ & 15 & 12 & 13,20 & 12 & 1,45 \\
\hline
\end{tabular}

Keterangan: Maks.: maksimum; Min.: minimum; Std. Deviasi: standar deviasi

\section{Hasil Uji Normalitas}

Berdasarkan uji normalitas menggunakan tes Saphiro-Wilk, didapatkan hasil bahwa data persepsi total responden dan skor perceived barrier memiliki distribusi normal. Hasil uji normalitas tersebut dapat dilihat di tabel $4 .^{11}$ di bawah ini:

Tabel 4. Hasil Uji Normalitas Variabelvariabel Persepsi, Modifyng Variable, dan Skor Kepatuhan

\begin{tabular}{lcc}
\hline \multicolumn{1}{c}{ Variabel } & $\mathbf{n}$ & $\mathbf{p}$ \\
\hline Skor Perceived & 30 & 0,043 \\
$\begin{array}{l}\text { Susceptibility } \\
\text { Skor Perceived Benefit }\end{array}$ & 30 & 0,004 \\
Skor Perceived Severity & 30 & 0,002 \\
Skor Perceived Barrier & 30 & $\left.0,120^{*}\right)$ \\
Skor External Cues to & 30 & 0,001 \\
Action & & \\
Skor Self Efficacy & 30 & 0,000 \\
Skor Persepsi Total & 30 & $\left.0,353^{*}\right)$
\end{tabular}

\begin{tabular}{|c|c|c|}
\hline Jenis kelamin & 30 & 0,000 \\
\hline Umur & 30 & 0,003 \\
\hline Lama bekerja & 30 & 0,000 \\
\hline Pendidikan & 30 & 0,000 \\
\hline Status Pekerjaan & 30 & 0,000 \\
\hline Jenis Bangsal & 30 & 0,000 \\
\hline $\begin{array}{l}\text { Riwayat pelatihan/ } \\
\text { Sosialisasi PPI }\end{array}$ & 30 & 0,000 \\
\hline $\begin{array}{l}\text { Riwayat Cidera Benda } \\
\text { Tajam }\end{array}$ & 30 & 0,000 \\
\hline $\begin{array}{l}\text { Riwayat Kontak Cairan } \\
\text { Tubuh Pasien }\end{array}$ & 30 & 0,000 \\
\hline Riwayat tertular HAIs & 30 & 0,000 \\
\hline $\begin{array}{l}\text { Skor Kepatuhan Hand } \\
\text { Hygiene }\end{array}$ & 30 & 0,000 \\
\hline
\end{tabular}

*) distribusi normal $(p>0,05)$

Uji Komparasi $(p=0,035)$ 
Oleh karena data-data yang diuji memiliki distribusi yang abnormal, maka dilakukan uji komparasi Mann Witney dan Kruskal Wallis. Terdapat hasil komparasi yang signifikan sebagai berikut: (a) Terdapat perbedaan bermakna dalam kepatuhan hand hygiene $(p=0,035)$ berdasarkan jenis kelamin dan di mana wanita memiliki kepatuhan lebih tinggi. (b) Terdapat perbedaan bermakna dalam kepatuhan hand hygiene $(\mathrm{p}=0,002)$ di mana staf yang bekerja di ICU memiliki kepatuhan lebih tinggi. (c) Terdapat perbedaan bermakna antara staf yang memiliki riwayat kontak cairan tubuh $(\mathrm{p}=0,049)$ dalam kepatuhan hand hygiene, di mana yang memiliki riwayat kontak memiliki kepatuhan lebih tinggi.
Pada hasil uji asumsi klasik, tidak terdapat multikolienaritas (seluruh variabel independen memiliki nilai tolerance $>0,1(10 \%)$ dan VIF $<10)$ serta tidak terdapat heteroskedisitas yang dapat diketahui dari tidak adanya pola yang jelas serta titiktitik menyebar acak di atas dan di bawah 0 pada sumbu y scatter plot. Autokorelasi tidak diujikan mengingat penelitian ini menggunakan metode cross sectional (bukan time series). ${ }^{12}$

Hanya variabel tempat kerja yang berpengaruh terhadap kepatuhan hand hygiene dengan $\mathrm{p}=0,000 \quad(\mathrm{Y}=7,281-2,448 X$ tempat kerja; $\mathrm{R}=0,655$; $\mathrm{R} 2=0,429 ; \mathrm{SEE}=1,3401$ )

\section{Analisis Regresi Linear Berganda}

\section{Tabel 5}

Hasil Uji Regresi Linear Berganda Variabel-variabel Modifikasi dan Persepsi terhadap Skor Hand Hygiene

\begin{tabular}{lccc}
\hline \multicolumn{1}{c}{ Skor Hand Hygiene } & Koefisien & t & p \\
\hline Step 1 & & & 0,757 \\
Konstanta & $-1,526$ & $-0,313$ & 0,762 \\
Skor Self Efficacy $\left(\mathrm{X}_{5}\right)$ & $-0,089$ & $-0,308$ & 0,084 \\
Jenis kelamin $\left(\mathrm{X}_{7}\right)$ & 1,049 & 1,817 & 0,848 \\
Umur $\left(\mathrm{X}_{8}\right)$ & 0,070 & 0,195 & 0,967 \\
Status pekerjaan $\left(\mathrm{X}_{11}\right)$ & 0,024 & 0,042 & 0,004 \\
Tempat Kerja $\left(\mathrm{X}_{12}\right)$ & 2,047 & 3,213 & 0,521 \\
Riwayat pelatihan PPI $\left(\mathrm{X}_{13}\right)$ & 0,802 & 0,653 & 0,533 \\
Riwayat cidera benda tajam $\left(\mathrm{X}_{14}\right)$ & 0,498 & 0,635 & 0,818 \\
Riwayat kontak cairan tubuh $\left(\mathrm{X}_{15}\right)$ &,- 183 & $-0,233$ & 0,464 \\
Riwayat menderita HAIs $\left(\mathrm{X}_{16}\right)$ & 0,502 & 0,746 & \\
\hline Step 2 & & & 0,000 \\
Konstanta & 7,281 & 7,745 & 0,000 \\
Tempat Kerja $\left(\mathrm{X}_{12}\right)$ & $-2,448$ & $-4,584$ & \\
\hline
\end{tabular}

\section{Keterangan:}

Step 1: $\mathrm{R}=0,763$;

R Square $=0,583$;

$\mathrm{SEE}=1,3554$;

$\mathrm{p}($ uji $\mathrm{F})=0,017$

Step 2: $\mathrm{R}=0,655$;

$\mathrm{R}$ Square $=0,429$;

$\mathrm{SEE}=1,3401$;

$\mathrm{p}($ uji F $)=0,000$ 


\section{Pembahasan}

Dalam penelitian ini, kepatuhan staf dalam $\mathrm{HH}$ 46,29\%. Kondisi ini sesuai dengan rerata kepatuhan $\mathrm{HH}$ internasional $(40 \%){ }^{13}$ Pada banyak penelitian dijelaskan bahwa pengetahuan dan pendidikan tidaklah selalu berkorelasi dengan perilaku menerapkan $\mathrm{HH}$ secara benar. ${ }^{14}$ Sebagaimana pada penelitian ini, tidak didapatkan perbedaan bermakna berdasarkan tingkat pendidikan dan riwayat pelatihan/ sosialisasi PPI. Di sisi lain, terdapat perbedaan bermakna dalam kepatuhan HH berdasarkan kontak cairan tubuh pasien. Meskipun dalam penelitian ini tidak dapat dijadikan sebagai prediktor kepatuhan $\mathrm{HH}$, senada dengan hasil penelitian di Kanada melalui 2 tahun observasi langsung, kontak cairan menjadi prediktor kepatuhan $\mathrm{HH}$ tertinggi (OR 4,7; 95\% CI: 3,7-6,1). ${ }^{15}$ Dalam penelitian ini, perbedaan jenis kelamin menunjukkan perbedaan kepatuhan, di mana staf wanita lebih patuh dibandingkan pria. Seperti halnya Borchgrevink et al juga meneliti bahwa kepatuhan wanita $69,6 \%$, sedangkan pria $30,9 \%{ }^{16}$

Dalam hal kepatuhan terhadap HH, moment terbanyak yang dilewatkan adalah setelah hand rub 5x. Dalam berbagai penelitian disebutkan bahwa hand rub dengan alkohol memang memiliki efektifitas yang tinggi, namun setelah hand rub berulang ditambah dengan inefektifitas prosedur, maka prosedur ini menjadi sangat berkurang efektivitasnya. ${ }^{17}$ Hal ini perlu menjadi masukan dalam sosialisai/ pendidikan PPI terhadap staf.

Temuan dalam penelitian ini juga konsisten dengan penelitian lain, di mana ketidak patuhan staf terhadap HH paling tinggi adalah sebelum prosedur klinis (49 $\%) .{ }^{14}$ Tidak berbeda dengan penelitian lainnya, kepatuhan $\mathrm{HH}$ juga lebih tinggi setelah kontak pasien (OR 3,9; 95\% CI: 3,5-4,4) dibandingkan sebelum kontak. $^{15}$ Terkait dengan penggunaan hand scoen, banyak penelitian menunjukkan bahwa penggunaan hand scoen menurunkan kepatuhan HH. Penelitian oleh Whitby \& McLaws (2004) juga menunjukkan bahwa hanya $25 \%$ yang melakukan $\mathrm{HH}$ setelah mengenakan hand scoen. ${ }^{13}$

Prosedur $\mathrm{HH}$ yang dilakukan oleh sebagian besar responden dalam penelitian ini belum tepat. Dalam segi efektivitas/ ketepatan prosedur, hanya 1 dari 30 responden $(3,3 \%)$ yang melakukan hand wash dengan benar dan tidak ada responden yang melakukan hand rub dengan benar.

Penelitian dengan menggunakan teori HBM menunjukkan hasil beragam. Penelitian di RSUP Dr. Sardjito mendapatkan perceived barrier, benefit, susceptibility, severity, dan pengetahuan tidak dapat dijadikan prediktor kepatuhan. ${ }^{18}$ Penelitian di Cina menunjukkan bahwa kepatuhan staf yang rendah dipengaruhi oleh kurangnya pelatihan dan pengetahuan, diikuti level RS, barrier, rendahnya self efficacy, dan variabel modifikasi lain (pengalaman terpapar/ cidera, dan departemen tempat bekerja). ${ }^{19}$

Berdasarkan observasi, kepatuhan perawat ICU relatif lebih baik. Seperti halnya dalam penelitian-penelitian sebelumnya, hal ini dipengaruhi oleh banyak faktor, diantaranya jumlah pasien lebih sedikit, rasio perawat banding pasien lebih kecil, tingkat ketergantungan dan kontak pasien dengan perawat lebih tinggi, dan fasilitas PPI lebih dekat. ${ }^{14}$

Pettit \& Boyce (2011) menyatakan bahwa faktor-faktor yang umumnya berkontribusi dalam rendahnya kepatuhan staf terhadap kewaspadaan standar adalah kurangnya edukasi, beban kerja tinggi, kurangnya role model, serta kurangnya leadership. ${ }^{14}$ Hal ini tidak hanya menuntut peningkatan kesadaran dan pengetahuan staf, melainkan juga keterlibatan institusi kesehatan dan pendidikan, serta pemerintah untuk mendukung perubahan sistem dan kebijakan. ${ }^{4}$

\section{SIMPULAN}

Berdasarkan hasil penelitian, dapat disimpulkan bahwa tempat kerja memiliki pengaruh terhadap kepatuhan menrapkan $\mathrm{HH}$, di mana perawat ICU lebih patuh daripada bangsal lain. Terdapat perbedaan bermakna kepatuhan staf wanita, staf ICU, dan yang memiliki kontak terhadap cairan lebih tinggi dibanding staf pria, staf bangsal bedah, dan staf yang tidak memiliki riwayat kontak cairan. Diperlukan penelitian lebih lanjut dengan sampel lebih besar dan metode yang mampu mengukur persepsi staf lebih mendalam, serta mengkaji faktor lain yang lebih luas.

\section{DAFTAR PUSTAKA}

1. World Heath Organization (WHO), 2002, Prevention of hospital-acquired infections; a practical guide; 2nd edition (Ducel, G.; Fabry, J.; 
Nicolle, L. [Eds.]). Diakses dari http://www.who.int/ emc pada 8 Agustus 2011.

2. WHO, 2010, The burden of health careassociated infection worldwide. Diakses dari www.who.int/gpsc/country work/summary_20100430_en.pdf pada 26 September 2011.

3. Departemen Kesehatan Republik Indonesia (Depkes RI), 2007, Pedoman manajerial pencegahan dan pengendalian infeksi di rumah sakit dan fasilitas pelayanan kesehatan lainnya, Depkes RI, Jakarta.

4. Jarvis, W (Eds.), 2007, Bennet and Brachman's hospital infection, 5th edition, Lippincott William and Wilkins, Philadelphia.Denison, Julie, 1996, Behavior Change; A Summary of Four Major Theories. Diakses dari http://ww2.fhi.org/en/aids/aidscap/aidspubs/behres/bcr4theo.html pada 26 September 2011.

5. Tim PPI RSUP Dr. Sardjito, 2011, Daftar tilik kepatuhan hand hygiene.

6. WHO, 2006, WHO guidelines for hand hygiene in health care (advanced draft). Diakses dari http://www.who.int/patientsefety/information_ce n-

tre/Last_April_versionHH_Guidelines $\% 5 \mathrm{~b} 3 \% 5 \mathrm{~d}$. pdf pada 26 September 2011.

7. WHO, 2004, Practical guidelines for infection control in health care facilities. Diakses dari http://www.whosea.org pada 13 September 2011.

8. WHO, 2008, Revised injection safety assesment tool.

9. Riyanto, Agus, 2010, Aplikasi metodologi penelitian kesehatan, Nuha Medika, Yogyakarta.

10. Dahlan, S, 2010, Evidence based medicine; mendiagnosis dan menatalaksana 13 penyakit statistik: disertai aplikasi program stata, Sagung Seto, Jakarta.

11. Yusuf, MAN, 2003, Modul terapan: analisis data multivariat, konsep dan aplikasi regresi linear ganda.

12. Flores, A; Pevalin, D,2007, 'Glove Use and Compliance with Hand Hygiene,' Nursing Times; 103: 38, 46-48.

13. Creedon, SA et al, 2008, 'Hand hygiene compliance: exploring variations in practice between hospitals', Nursing Times; 104: 49, 32 35.
14. Lebovic, G et al, 2013, 'Predictors of hand hygiene compliance in the era of alcohol-based hand rinse,' J Hosp Infect, 2013 Apr;83(4):27683.

15. Borchgrevink et al, 2011, 'Handwashing compliance rates and predictors in a college town environment', International CHRIE ConferenceRefereed Track. Paper 22

16. Dyer, DL, Gerenraich, KB, Wadhams, PS, 1998, 'Testing a new alcohol-free hand sanitizer to combat infection.' AORN J 68 (2): 239-41, 2434, 247-51.

17. Widodo, W, 1996, Analisa situasional pelaksanaan program kebersihan dalam pencegahan infeksi nosokomial di IRNA I penyakit dalam RSUP dr. Sardjito Yogyakarta: tesis. Program Pascasarjana Prodi Ilmu Kesehatan Masyarakat, Universitas Gajah Mada, Yogyakarta.

18. Luo, Y, He, GP, Zhou, JW, \& Luo, Y, 2010, 'Factors impacting compliance with standard precautions in nursing, China', Int J Infect Dis, 2010 Dec;14(12):e1106-14 Epub 2010 Nov 10. Diakses dari http://www.ncbi.nlm.nih.gov/pubmed/21071254 pada 26 September 2011 